\title{
Use of Corneal hysteresis and Corneal Resistance Factor in Target Intraocular Pressure Estimation in Patients with Early Primary Open Angle Glaucoma
}

Moataz Sallam ( $\sim$ moataz.sallam@med.suez.edu.eg)

Suez Canal University Faculty of Medicine https://orcid.org/0000-0003-4759-4849

Mervat E. Elghareib

Suez Canal University Faculty of Medicine

\section{Research Article}

Keywords: Corneal biomechanics, Ocular response analyzer, Target intraocular pressure, Primary open angle glaucoma

Posted Date: May 26th, 2021

DOl: https://doi.org/10.21203/rs.3.rs-548892/v1

License: (c) (1) This work is licensed under a Creative Commons Attribution 4.0 International License.

Read Full License

Version of Record: A version of this preprint was published at International Ophthalmology on October 11th, 2021. See the published version at https://doi.org/10.1007/s10792-021-02070-y. 


\section{Abstract}

Purpose: To introduce a new method for estimation of the target intraocular pressure (TIOP) in naïve eyes with early primary open angle glaucoma (POAG) using Corneal hysteresis $(\mathrm{CH})$ and corneal resistance factor (CRF).

Methods: A prospective quasi-experimental study was conducted on naïve 90 eyes of 45 patients who were newly diagnosed with early primary open angle glaucoma (POAG). They were compared to 72 eyes of 36 normal subjects. The TIOP was determined for each eye. The IOP Goldmann (IOPg), IOP cornealcompensated (IOPcC), CH and CRF were estimated by Ocular Response Analyzer (ORA, Reichert) device. Measurements were taken for each patient prior to treatment and after 1, 3, 6, 9 and 12 months of receiving medications; either monotherapy or combination therapy.

Results: For all patients, there was a significant negative correlation $(p<0.05)$ between IOP, either IOPg or IOPcc, and $\mathrm{CH}$ while a significant positive relationship $(\mathrm{p}<0.05)$ existed between IOP and CRF. For patients with early POAG, The $\mathrm{CH}$ was significantly increased $(p \leq 0.001)$ while CRF was significantly decreased ( $p \leq 0.001)$ when TIOP was achieved. At IOP levels higher than TIOP, CH value was lower than $\mathrm{CRF}$ with a significant negative correlation between them in contrast to controls. This correlation was reversed on reaching TIOP and $\mathrm{CH}$ values became higher than $\mathrm{CRF}$ similar to controls.

Conclusion: $\mathrm{CH}, \mathrm{CRF}$ and IOP measured by ORA can be used for TIOP estimation. This provides us with a guide for assessing the effectiveness of medications introduced to patients with POAG.

\section{Key Messages}

1. Target intraocular pressure in patients with early primary open angle glaucoma could be determined by corneal hysteresis and corneal resistance factor as biomechanical parameters by following their value changes in accordance with intraocular pressure change.

2. we can depend, in practice, on the directly proportionate correlation between $\mathrm{CH}$ and $\mathrm{CRF}$ in determining the target IOP level at which $\mathrm{CH}$ becomes higher than CRF.

3. The IOP is always directly proportionate to $\mathrm{CRF}$ while inversely proportionate to $\mathrm{CH}$.

4. This gives us with a guidance for assessing the effectiveness of medications introduced to patients with POAG and may improve their health-related quality of life.

\section{Introduction}

The principal goal of glaucoma management is to lower the intraocular pressure (IOP) either by conservative or interventional measures [1]. Hence, the term "target IOP" has been established. It can be defined as the IOP level at which the glaucoma stabilizes with treatment, and, thus, the patient's quality of life is preserved [2]. Another definition is the IOP level at which the sum of the health-related quality of life (HRQOL) from preserved vision and the HRQOL from not having treatment side effects is maximized [3]. 
In practice, the definition of target IOP includes the highest IOP level in a given eye at which no clinically apparent optic neuropathy is likely to occur [4].

There are several factors to be considered when setting the target IOP. They include the stage of glaucoma, pre-treatment IOP, age and life expectancy, rate of progression during follow-up, presence of other risk factors such as exfoliations, the adverse effects and risks of treatment, and patient's preference [5]. Other factors, such as corneal hydration, connective tissue composition, and bioelasticity may contribute to the response of the corneoscleral shell to the force applied during the IOP measurement [6].

Documenting the corneal biomechanical properties of the cornea is crucial as they are considered a significant risk factor for development and progression of glaucoma [7].

The Ocular Response Analyzer (ORA) (Reichert Inc., Depew, New York) is a popular commercially available medical device capable of measuring corneal biomechanics in vivo. It allows measurement of Goldmann-correlated IOP (IOPg), which is correlated to Goldmann applanation tonometry IOP, and corneal-compensated IOP (IOPcC) which is derived from both IOP and corneal biomechanical data. The ORA supplies two additional parameters that reflect the biomechanical properties of the cornea and demonstrate an inter-individual variation of the corneal hysteresis $(\mathrm{CH})$ and corneal resistance factor (CRF) [8]. Several studies reported that IOPcc is more accurate indicator of true IOP than IOPg as it is unrelated to central corneal thickness $[7,9,10]$. Lower corneal hysteresis has been reported in previous research to be related to progressive glaucoma $[7,11-13]$.

Furthermore, $\mathrm{CH}$ and $\mathrm{CRF}$ were found to be lower among glaucoma patients than normal people and much lower in advanced stage of the disease $[14,15]$. But no researches yet studied the relationship between $\mathrm{CH}$ and $\mathrm{CRF}$ with changes in IOP or the role of corneal biomechanics in target IOP estimation.

Till now, there is no hard evidence for the concept or the methods used to determine the target IOP [16]. Therefore, our study aimed to describe a novel method for target intraocular pressure estimation in patients with early primary open angle glaucoma using the ocular response analyzer.

\section{Patients And Methods}

The study was conducted as a prospective quasi-experimental study after being approved by our Research Ethics Committee (REC) according to the principles of the Declaration of Helsinki [17].

A total of 125 eyes of 65 consecutive patients with elevated intraocular pressure (IOP) were initially enrolled in the study and assessed at Ophthalmology Outpatient Clinic, Suez Canal University Hospital in the period from January 2018 till December 2019. The study included patients older than 40 years who were newly diagnosed, still untreated, and prone to therapy either with monotherapy (travoprost $0.004 \%$ one drop once daily in the evening) or combination therapy (travoprost $0.004 \%+$ timolol $0.5 \%$ one drop once daily in the evening). All patients having early glaucomatous damage as defined by HodappParrish-Anderson criteria for staging glaucoma using Humphrey visual field testing [18] were included in 
the study. These criteria are: (1) Glaucoma hemifield test outside normal limits on at least two consecutive occasions. (2) A cluster of 3 or more non-edge points in a location typical for glaucoma, all of which are depressed on pattern standard deviation (PSD) at $\mathrm{P}<5 \%$ level and one which is depressed at $\mathrm{P}<1 \%$ level, on two consecutive occasions. (3) Corrected pattern standard deviation (CPSD) that occurs in less than $5 \%$ of normal individuals on two consecutive fields. Glaucoma risk factors in our study cohort involved hypertension, diabetes mellitus and smoking. Patients suffering from any other types of glaucoma, patients on previous regular treatment or previous ocular surgery, patients with corneal pathology or refractive error of more than \pm 4 diopters or aphakic patients were excluded from the study. Forty-five (45) patients with 90 eyes out of 65 patients (125 eyes) were eligible for the study (POAG group) (Fig. 1). They were compared to 72 eyes of 36 normal individuals that came for regular checkup (control group).

At baseline, all participants had full history taking and complete ophthalmic examination, including slitlamp biomicroscopy (Topcon, DC-3, Japan) for anterior and posterior segment, Goldmann applanation tonometry (GAT), gonioscopy, ultrasound pachymetry (Sonomed, USA), visual field testing (HumphreyZeiss Systems, Dublin, CA), ocular response analyzer testing (Reichert Corp., Buffalo, NY) and spectral domain optical coherence tomography (SD-OCT, Topcon, Triton plus, version 10.07, Japan). The IOP was measured in the morning between 10 and 11 o'clock either with GAT or ORA.

Visual field sensitivity was tested using the 30 - 2 Swedish Interactive Threshold Algorithm (SITA) [19] and standard automated perimetry (SAP) program of the Humphrey Field Analyzer. All participants had to have a reliable fixation loss, false-positive, and false-negative error $<10 \%$.

Corneal biomechanical properties and IOP were measured using Ocular Response Analyzer. Device settings and calibration were reviewed. Proper patient alignment was ensured. Readings were examined graphically, and those with poor-quality applanation signals (multiple applanation spikes, asymmetric signals or waveform score (WS) below 7 [20]) were discarded. Four good-quality measurements were recorded by the device for each eye and the results were averaged. Corneal biomechanical properties included corneal hysteresis $(\mathrm{CH})$ and corneal resistance factor (CRF). The $\mathrm{CH}$ is derived from the difference between the inward and outward applanation pressures (P1-P2) and thought to represent the viscous-damping capacity of the cornea. The CRF is derived from the relationship between both P1 and P2 and central corneal thickness. It represents a measurement of corneal resistance [21]. The intra-ocular pressure (IOP) measured by the ORA included two values, the first IOP value is an estimate of Goldmann $\mathrm{IOP}(\mathrm{IOPg})$ and the second IOP value is an estimate of IOP corrected for the biomechanical properties of the cornea (IOPcC).

Patients were assessed at time of diagnosis (before start of the treatment) as a baseline assessment then regularly assessed after receiving medications at 1, 3, 6, 9 and 12 months follow up period. The target IOP was estimated separately for each eye of every patient according to European Glaucoma Society guidelines considering stage of glaucoma, IOP before treatment, age and life expectancy, rate of progression during follow up, side effects and risks of treatments, status of other eye and patient 
preference [22]. Medications were given to the patients and the responses were followed up till IOPcC reach the predetermined target value.

A baseline peripapillary retinal nerve fiber layer (pRNFL) thickness was measured using SD-OCT for documenting glaucomatous retinal nerve fiber layer loss. Average nerve fiber layer thickness; superior, inferior, temporal, and nasal quadrants thicknesses were assessed in the 12 clock hours vectors.

Analysis of optic nerve head $(\mathrm{ONH})$ was done. Scan covers an area of $6 \times 6 \mathrm{~mm}$ centered on the disc with a scan density of 512 (vertical) and 256 (horizontal) scans. Scans with motion artifact, poor quality or incorrect segmentation were rejected and repeat scans were acquired.

Statistical analyses were performed with SPSS software (SPSS for Windows Version 26.0; SPSS Inc., Chicago, IL). Data of all patients was normally distributed. Demographic characteristics and ocular response analyzer parameters were compared between POAG patients and controls using t-test.

Percentages were calculated for the qualitative data while mean and standard deviation were calculated for quantitative data. The Chi-square test was applied for the comparison of the categorical variables in both groups. For POAG patients, parametric analyses between means of IOP, CH and CRF, at baseline and at $1,3,6,9$ and 12 months of treatment, were evaluated with t-test. The correlations between ORA parameters were calculated using Pearson correlation test and presented on scatter plots. Changes in ORA parameters through the follow up period were presented as line graphs. $P$ value less than 0.05 was considered statistically significant.

\section{Results}

Our study included patients with early primary open angle glaucoma (POAG group) who had early glaucomatous damage on visual field ( $n=90$ eyes).

One hundred and twenty-five (125) eyes were initially enrolled. Thirty-five (35) eyes were excluded as they were aphakic $(n=5)$, diagnosed with pseudoexfoliation glaucoma $(n=3)$, chronic angle closure glaucoma $(n=4)$, moderate POAG $(n=7), 3$ severe POAG $(n=3)$ or ocular hypertension $(n=5)$ or underwent previous ocular surgery $(n=8)$. The control group involved 72 eyes of 36 normal subjects.

The mean target IOP determined according to the European glaucoma society guidelines was $(15.50 \pm$ $0.71 \mathrm{mmHg}$ ). The IOP measured by GAT (IOP $\mathrm{GAT})$ showed nonsignificant difference with IOPg measured by ORA for study and control groups ( $p=0.596$ and 0.113 respectively).

Table 1 summarized the preoperative clinical and demographic characteristics of our study groups. 
Table 2

Ocular response analyzer parameters between groups at baseline and after achieving target intra-ocular pressure (TIOP) by treatment.

\begin{tabular}{|c|c|c|c|}
\hline & POAG group & Control group & $P$ value \\
\hline IOPg, mmHg & $26.04 \pm 3.00$ & $15.00 \pm 1.24$ & $<0.001^{\star}$ \\
\hline Baseline & $15.43 \pm 1.09$ & $14.89 \pm 1.21$ & $0.060 * \star$ \\
\hline \multicolumn{4}{|l|}{ After 12 months of treatment } \\
\hline IOPcc, mmHg & $29.24 \pm 3.81$ & $15.50 \pm 1.15$ & $<0.001^{\star}$ \\
\hline Baseline & $15.47 \pm 1.32$ & $15.00 \pm 1.18$ & $0.050 * \star$ \\
\hline \multicolumn{4}{|l|}{ After 12 months of treatment } \\
\hline $\mathrm{CH}, \mathrm{mmHg}$ & $6.81 \pm 1.70$ & $10.15 \pm 1.00$ & $<0.001^{\star}$ \\
\hline Baseline & $9.79 \pm 0.89$ & $10.19 \pm 1.08$ & $0.012^{\star \star}$ \\
\hline \multicolumn{4}{|l|}{ After 12 months of treatment } \\
\hline $\mathrm{CRF}, \mathrm{mmHg}$ & $10.55 \pm 1.07$ & $9.00 \pm 1.02$ & $<0.001^{\star}$ \\
\hline Baseline & $8.25 \pm 0.95$ & $9.08 \pm 0.98$ & $<0.001 \star \star$ \\
\hline \multicolumn{4}{|l|}{ After 12 months of treatment } \\
\hline \multicolumn{4}{|l|}{ WS } \\
\hline Baseline & $7.61 \pm 0.50$ & $8.65 \pm 0.51$ & $<0.001^{*}$ \\
\hline After 12 months of treatment & $8.56 \pm 0.38$ & $8.44 \pm 0.50$ & $0.070 * \star$ \\
\hline \multicolumn{4}{|c|}{ All values are expressed as mean \pm standard deviation (SD) } \\
\hline \multicolumn{4}{|c|}{$\begin{array}{l}\text { POAG: Primary open angle glaucoma; IOPg: Goldmann intraocular pressure; IOPcC: cornea corrected } \\
\text { intraocular pressure; CH: Corneal hysteresis; CRF: Corneal resistance factor; WS: waveform score. }\end{array}$} \\
\hline \multicolumn{4}{|c|}{ * Baseline ORA parameter of POAG patients compared to that of normal controls. } \\
\hline \multicolumn{4}{|c|}{$\begin{array}{l}\text { ** The ORA parameter of POAG patients at the end of follow up period (at target IOP levels) compared } \\
\text { to that of normal controls. }\end{array}$} \\
\hline$P$ value is based on $t$ test. & & & \\
\hline
\end{tabular}

For the POAG patients, The IOPcc reached target levels after one month of treatment. From this point and forward, its measurement and $\mathrm{IOPg}, \mathrm{CH}$ and $\mathrm{CRF}$ measurements were kept stable with nonsignificant differences $(p>0.05)$ till the end of the one year follow up. Moreover, the IOPcc was significantly higher than the IOPg at baseline $(p<0.001)$, while after IOP control, the differences decreased to nonsignificant values ( $p=0.834$ ) (Fig. 2). As indicated by the line graph in Fig. 2, at baseline, the $\mathrm{CH}$ is lower than the $\mathrm{CRF}$. By reaching the target IOP, the $\mathrm{CH}$ was higher than the $\mathrm{CRF}$ which was similar to the results of the subjects of the control group, (Table 2). 
Comparison of ORA parameters at baseline and after 12 months of treatment revealed significant decrease in IOPg, IOPcc and CRF ( $p \leq 0.001)$ that was associated with significant increase in $\mathrm{CH}(\mathrm{p} \leq$ 0.001). Additionally, the IOPg and the IOPcc showed nonsignificant differences when compared to the target IOP determined based on the European glaucoma society guidelines $(p=0.708$ and 0.879 respectively).

There was a significant negative correlation $(\mathrm{p}<0.05)$ between IOP, either IOPg or IOPcc, and $\mathrm{CH}$ among POAG patients and controls. In contrast, a significant positive correlation $(p<0.05)$ existed between IOP and $\mathrm{CRF}$ in both groups (Fig. 3a-c).

Our study concluded that there were significant negative ( $\mathrm{p}$ value $<0.05)$ correlations between $\mathrm{CH}$ and $\mathrm{CRF}$ at baseline before onset of treatment. This was in contrast to the normal controls whose $\mathrm{CH}$ and $\mathrm{CRF}$ showed a significant positive correlation ( $p$ value $<0.05$ ). However, when target IOP was achieved with medications, the CRF showed an upward trend with increasing $\mathrm{CH}(\mathrm{p}$ value $<0.05)$ similar to the controls (Fig. 3a-c).

Visual field indices together with average, superior and inferior RNFL thicknesses revealed significant differences when compared to controls. However, following up the glaucoma progression in the study group showed nonsignificant differences when comparing the 12 months changes in visual field indices and pRNFL thickness from baseline, (Table 3). 
Table 3

Characteristics of visual field indices and peripapillary RNFL thickness for study and control groups.

Baseline

POAG group

Control group $\mathrm{P} 1^{*}$

After 12 months of treatment

\begin{tabular}{|c|c|c|c|c|c|}
\hline & POAG group & Control group & $\mathrm{P} 1 *$ & POAG group & $\mathrm{P} 2 *$ \\
\hline \multicolumn{6}{|l|}{ Visual field indices } \\
\hline $\mathrm{MD}(\mathrm{dB})$ & $-3.84 \pm 1.37$ & $-0.51 \pm 0.67$ & $<0.001$ & $-3.90 \pm 1.28$ & 0.803 \\
\hline PSD (dB) & $5.49 \pm 1.00$ & $1.45 \pm 0.45$ & 0.007 & $5.60 \pm 1.10$ & 0.907 \\
\hline CPSD (dB) & $4.38 \pm 0.95$ & $1.38 \pm 0.84$ & 0.015 & $4.47 \pm 1.03$ & 0.923 \\
\hline \multicolumn{6}{|c|}{ Peripapillary RNFL thickness, $\mu \mathrm{m}$} \\
\hline Average thickness & $95.80 \pm 4.18$ & $99.21 \pm 3.98$ & $<0.001$ & $95.58 \pm 4.18$ & 0.738 \\
\hline Superior quadrant & $108.08 \pm 6.25$ & $113.58 \pm 9.49$ & $<0.001$ & $107.94 \pm 6.25$ & 0.886 \\
\hline Inferior quadrant & $108.95 \pm 8.21$ & $112.79 \pm 7.33$ & 0.023 & $108.81 \pm 8.21$ & 0.914 \\
\hline Nasal quadrant & $86.52 \pm 7.04$ & $88.47 \pm 6.24$ & 0.365 & $86.40 \pm 7.04$ & 0.907 \\
\hline Temporal quadrant & $78.92 \pm 8.61$ & $81.63 \pm 7.22$ & 0.178 & $78.72 \pm 8.61$ & 0.876 \\
\hline \multicolumn{6}{|c|}{ RNFL: Peripapillary retinal nerve fiber layer; POAG: Primary open angle glaucoma; MD: Mean deviatio } \\
\hline \multicolumn{6}{|c|}{ P1, Baseline comparison between POAG patients and control groups } \\
\hline \multicolumn{6}{|c|}{ P2, POAG patients at baseline versus end of follow up period } \\
\hline \multicolumn{6}{|l|}{ * $t$ test } \\
\hline
\end{tabular}

\section{Discussion}

This study is a prospective quasi-experimental study that included early glaucomatous patients without treatment as a study group (90 eyes) versus normal subjects as control group (72 eyes).

Our observations confirmed that corneal biomechanical properties can be used for target IOP estimation.

Ocular response analyzer was performed for all patients before onset of treatment and repeated through one year follow up period at 1, 3, 6, 9 and 12 months after receiving medications. Ocular response analyzer is highly valuable device that measures corneal hysteresis $(\mathrm{CH})$, a dependable predictor of glaucoma progression as evidenced by De Moraes et al. [23] and Chandrasekaran et al. [24] who reported that lower corneal hysteresis is associated with rapid glaucoma progression. Corneal hysteresis is an indication of the corneal biomechanical properties differing from corneal thickness or topography, which are geometrical characteristics. 
Patients were assessed for achieving target IOP after taking medications after four weeks to ensure maximum drug effect and patients' response as recommended by the European Glaucoma Society guidelines [22]. Then treatment was modified accordingly.

Eyes with lower $\mathrm{CH}$ had faster rates of visual field loss than those with higher $\mathrm{CH}$ [7]. Additionally, ocular response analyzer provides corneal compensated intraocular pressure (IOPcc), a better indication of the true pressure, proven to be less influenced by corneal properties than that measured by Goldmann applanation tonometry (GAT) [9]. This met agreement with our findings as IOPcc was higher than the Goldmann IOP. So, we used the IOPCC as an indication for the real IOP for our glaucoma patients aiming to decreasing it to the target value.

In our study, the IOPg and IOP $\mathrm{IAT}_{\mathrm{GT}}$ were nearly similar with nonsignificant differences. This finding confirmed the results of Ehrlich et al [25] who concluded that IOP ${ }_{\text {GAT }}$ and IOPg showed good agreement and the IOPg may be substituted for GAT. So, we depended on IOPg in comparisons as an indicative for the Goldmann tonometry.

Our study reported that $\mathrm{CH}$ and $\mathrm{CRF}$, at baseline, were lower among patients with POAG than normal people. This could be explained as the elevated IOP affects the dampening capacity and bioelasticity of the cornea. This finding was matched with the results of Karin R Pillunat et al [14].

Furthermore, the $\mathrm{CH}$ is inversely correlated to the IOP elevation while the CRF is directly correlated to the increase in IOP. Our analysis confirmed that $\mathrm{CH}$ and CRF are inversely correlated to each other as much as the IOP is higher than the levels of target IOP. Nonetheless, similar to control subjects, $\mathrm{CH}$ is directly proportionate to CRF when the target IOP is achieved. This indicates that the IOP controls the relationship between $\mathrm{CH}$ and $\mathrm{CRF}$.

In practice, this correlation can confirm target IOP achievement. Moreover, our data suggested that when IOP is higher than its target levels, even if it is within average range, the $\mathrm{CH}$ is always lower than $\mathrm{CRF}$ in contrast to normal controls. But only at target IOP levels, the $\mathrm{CH}$ restore its normal value and be higher than the CRF similar to controls.

In other words, when $\mathrm{CH}$ became higher than CRF after treating POAG, the recorded IOP is consequently the target pressure.

The $\mathrm{CH}$ and $\mathrm{CRF}$, at the end of follow up period and after IOP control, were significantly lower among our POAG patients than normal controls. In accordance to our findings, Deol et al in 2015 reviewed corneal hysteresis and its relevance to glaucoma. They reported that glaucomatous damage and glaucoma progression is associated with low corneal hysteresis. In addition, corneal hysteresis is dynamically changing and may increase after IOP-lowering interventions are implemented [26]. These results built on existing evidence which supports that corneal hysteresis is significantly lower in eyes with POAG than normal eyes [21, 27]. Sullivan-Mee et al [15] demonstrated that corneal hysteresis was significantly lower in patients with POAG than with ocular hypertension, glaucoma suspect, or normal subjects. Similar to 
our results, they concluded that corneal hysteresis could discriminate between the POAG and the normal controls.

The association between $\mathrm{CH}$ and IOP in our study have met agreement with Liang et al [28] who reviewed and summarized the characteristics of corneal hysteresis $(\mathrm{CH})$ and its association with glaucoma. They concluded that $\mathrm{CH}$ can be used as a predictor of glaucoma risk. The $\mathrm{CH}$ also plays an important role in the diagnosis and treatment of glaucoma as it increases when the intraocular pressure decreases and decreases when the intraocular pressure increases [28].

Despite our findings matched with various studies [29-31]; which concluded that the use of prostaglandin (PG) analogues has no effect on the corneal biomechanical properties, Meda et al [32] found a significant increase in $\mathrm{CH}$ and $\mathrm{CRF}$ with chronic $\mathrm{PG}$ analogues use. This mismatched results could be attributed to the fact that Meda et al evaluated patients already on treatment for up to seven years, while we evaluated naïve eyes at the start of treatment to control the glaucoma and achieve the target IOP. Accordingly, it seems that the changes in the corneal biomechanics were related to the change of the IOP rather than the effect of the drugs used. Furthermore, they used smaller sample in their study $(n=70)$ and exposed them to drug wash out in one eye for 6 weeks which is considered an ethical concern.

Stability of IOP and corneal biomechanics of our POAG patients through the one year follow up period was confirmed by nonsignificant differences in visual filed indices and pRNFL thicknesses when comparing baseline assessment to that at the end of the 12 months follow up.

Because our glaucoma patients were detected early and before visual fields defects occurred, the baseline PRNFL thickness depression was small and nonsignificant. This can be explained by the results of Miki A et al.[33] who reported that eyes which did not developed visual field defect had an approximately 2.5 times slower rate of RNFL thickness loss compared to eyes which developed them. Moreover, the mean rate of global RNFL loss in eyes which did not develop visual field damage was $0.82 \mu \mathrm{m} /$ year.

We have to report that there is no evidence-based research reporting the relation between $\mathrm{CH}$ and $\mathrm{CRF}$ and target IOP in glaucoma management.

As our study had some limitations regarding enrollment of only patients with POAG, we recommend further research to evaluate the role of corneal biomechanics in controlling other types of glaucoma. As patients were observed for only one year, longer longitudinal follow-up to precisely assess the stability of corneal biomechanics with IOP control and to study the effect of treatment on $\mathrm{CH}$ and CRF are recommended. However, the current study was a prospective study introducing a new tool in determining target IOP in POAG patients. Also, to ensure accuracy, we depended on multiple measurement with four sequential puffs and the measures were averaged. Only one ophthalmologist carried out the measurements and no patients were lost to follow-up. 
In conclusion, we can depend, in practice, on the directly proportionate correlation between $\mathrm{CH}$ and $\mathrm{CRF}$ in determining the target IOP level at which $\mathrm{CH}$ becomes higher than CRF. This provides us with a guide for assessing the effectiveness of medications introduced to patients with POAG and may improve the quality of their lives.

\section{Declarations}

\section{Funding}

This research did not receive any specific grant from funding agencies in the public, commercial, or notfor-profit sectors.

\section{Conflict of interest}

The authors declare no conflict of interest.

\section{Availability of data and materials}

The datasets used and/or analysed during the current study are available from the corresponding author on reasonable request.

\section{Acknowledgements}

Not applicable

\section{Consent for publication}

Not applicable

\section{Consent to participate}

Informed consent was obtained from all individual participants included in the study. Patients who were unwilling to provide an informed consent were excluded from the study

\section{Statement of ethics}

This study was approved by our National and Institutional Research Ethics Committee (REC) in accordance with the tenets of the Declaration of Helsinki.

\section{References}

1. Sihota R, Angmo D, Ramaswamy D, Dada T (2018) Simplifying "target" intraocular pressure for different stages of primary open-angle glaucoma and primary angle-closure glaucoma. Indian $\mathrm{J}$ Ophthalmol 66:495-505. https://doi.org/10.4103/ijo.IJO_1130_17 
2. Prum BE, Rosenberg LF, Gedde SJ et al (2016) Primary open-angle glaucoma preferred practice pattern ${ }^{\circledR}$ guidelines. Ophthalmology 123:P41-P111

3. Quaranta L, Riva I, Gerardi C et al (2016) Quality of Life in Glaucoma: A Review of the Literature. Adv Ther 33:959-981. https://doi.org/10.1007/s12325-016-0333-6

4. Parikh RS, Parikh SR, Navin S et al (2008) Practical approach to medical management of glaucoma. Indian J Ophthalmol 56:223-230. https://doi.org/10.4103/0301-4738.40362

5. Heijl A, Leske MC, Bengtsson B et al (2002) Reduction of intraocular pressure and glaucoma progression: results from the Early Manifest Glaucoma Trial. Arch Ophthalmol (Chicago, III 1960) 120:1268-1279. https://doi.org/10.1001/archopht.120.10.1268

6. Yaoeda K, Fukushima A, Shirakashi M, Fukuchi T (2016) Comparison of intraocular pressure adjusted by central corneal thickness or corneal biomechanical properties as measured in glaucomatous eyes using noncontact tonometers and the Goldmann applanation tonometer. Clin Ophthalmol 10:829-834. https://doi.org/10.2147/OPTH.S106836

7. Medeiros FA, Meira-Freitas D, Lisboa R et al (2013) Corneal hysteresis as a risk factor for glaucoma progression: a prospective longitudinal study. Ophthalmology 120:1533-1540. https://doi.org/10.1016/j.ophtha.2013.01.032

8. Brown KE, Congdon NG (2006) Corneal structure and biomechanics: impact on the diagnosis and management of glaucoma. Curr Opin Ophthalmol 17:338-343. https://doi.org/10.1097/01.icu.0000233951.01971.5b

9. Medeiros FA, Weinreb RN (2006) Evaluation of the influence of corneal biomechanical properties on intraocular pressure measurements using the ocular response analyzer. J Glaucoma 15:364-370. https://doi.org/10.1097/01.ijg.0000212268.42606.97

10. Johnson CS, Mian SI, Moroi S et al (2007) Role of corneal elasticity in damping of intraocular pressure. Invest Ophthalmol Vis Sci 48:2540-2544. https://doi.org/10.1167/iovs.06-0719

11. Congdon NG, Broman AT, Bandeen-Roche $\mathrm{K}$ et al (2006) Central corneal thickness and corneal hysteresis associated with glaucoma damage. Am J Ophthalmol 141:868-875. https://doi.org/10.1016/j.ajo.2005.12.007

12. De Moraes CVG, Hill V, Tello C et al (2012) Lower corneal hysteresis is associated with more rapid glaucomatous visual field progression. Ophthalmology 141:868-875. https://doi.org/10.1097/IJG.0b013e3182071b92

13. Park JH, Jun RM, Choi K-R (2015) Significance of corneal biomechanical properties in patients with progressive normal-tension glaucoma. Br J Ophthalmol 99:746-751. https://doi.org/10.1136/bjophthalmol-2014-305962

14. Pillunat KR, Hermann C, Spoerl E, Pillunat LE (2016) Analyzing biomechanical parameters of the cornea with glaucoma severity in open-angle glaucoma. Graefe's Arch Clin Exp Ophthalmol $=$ Albr von Graefes Arch fur Klin Exp Ophthalmol 254:1345-1351. https://doi.org/10.1007/s00417-0163365-3 
15. Sullivan-Mee M, Billingsley SC, Patel AD et al (2008) Ocular Response Analyzer in subjects with and without glaucoma. Optom Vis Sci 85:463-470. https://doi.org/10.1097/OPX.0b013e3181784673

16. Thomas R, Thomas S, Chandrashekar G (1998) Gonioscopy. Indian J Ophthalmol 46:255-261

17. (2013) World Medical Association Declaration of Helsinki: ethical principles for medical research involving human subjects. JAMA 310:2191-2194. https://doi.org/10.1001/jama.2013.281053

18. Hodapp E, Parrish RK, Anderson DR (1993) Clinical Decisions in Glaucoma. Mosby Company, Maryland Heights

19. Bengtsson B, Olsson J, Heijl A, Rootzén H (1997) A new generation of algorithms for computerized threshold perimetry, SITA. Acta Ophthalmol Scand 75:368-375. https://doi.org/10.1111/j.16000420.1997.tb00392.x

20. Ayala M, Chen E (2012) Measuring corneal hysteresis: threshold estimation of the waveform score from the Ocular Response Analyzer. Graefe's Arch Clin Exp Ophthalmol = Albr von Graefes Arch fur Klin Exp Ophthalmol 250:1803-1806. https://doi.org/10.1007/s00417-012-2053-1

21. Kaushik S, Pandav SS (2012) Ocular Response Analyzer. J Curr glaucoma Pract 6:17-19. https://doi.org/10.5005/jp-journals-10008-1103

22. (2017) Terminolog yand guidelines for glaucoma. Br J Ophthalmol 4th editio: https://doi.org/10.1136/bjophthalmol-2016-EGSguideline.01

23. De Moraes CVG, Hill V, Tello C et al (2012) Lower corneal hysteresis is associated with more rapid glaucomatous visual field progression. J Glaucoma 21:209-213.

https://doi.org/10.1097/IJG.0b013e3182071b92

24. Chandrasekaran S, Uppuluri S, Sadek H et al (2020) Fluctuations of the Ocular Response Analyzer in measuring Corneal Hysteresis of subjects with and without Glaucoma and other Systemic Conditions. Invest Ophthalmol Vis Sci 61:4710

25. Ehrlich JR, Haseltine S, Shimmyo M, Radcliffe NM (2010) Evaluation of agreement between intraocular pressure measurements using Goldmann applanation tonometry and Goldmann correlated intraocular pressure by Reichert's ocular response analyser. Eye (Lond) 24:1555-1560. https://doi.org/10.1038/eye.2010.83

26. Deol M, Taylor DA, Radcliffe NM (2015) Corneal hysteresis and its relevance to glaucoma. Curr Opin Ophthalmol 26:96-102. https://doi.org/10.1097/ICU.0000000000000130

27. Mangouritsas G, Morphis G, Mourtzoukos S, Feretis E (2009) Association between corneal hysteresis and central corneal thickness in glaucomatous and non-glaucomatous eyes. Acta Ophthalmol 87:901-905. https://doi.org/10.1111/j.1755-3768.2008.01370.x

28. Liang L, Zhang R, He L-Y (2019) Corneal hysteresis and glaucoma. Int Ophthalmol 39:1909-1916. https://doi.org/10.1007/s10792-018-1011-2

29. Agarwal DR, Ehrlich JR, Shimmyo M, Radcliffe NM (2012) The relationship between corneal hysteresis and the magnitude of intraocular pressure reduction with topical prostaglandin therapy. $\mathrm{Br}$ J Ophthalmol 96:254-257. https://doi.org/10.1136/bjo.2010.196899 
30. Tsikripis P, Papaconstantinou D, Koutsandrea C et al (2013) The effect of prostaglandin analogs on the biomechanical properties and central thickness of the cornea of patients with open-angle glaucoma: a 3-year study on 108 eyes. Drug Des Devel Ther 7:1149-1156. https://doi.org/10.2147/DDDT.S50622

31. Bolívar G, Sánchez-Barahona C, Teus M et al (2015) Effect of topical prostaglandin analogues on corneal hysteresis. Acta Ophthalmol 93:e495-e498. https://doi.org/10.1111/aos.12689

32. Meda R, Wang Q, Paoloni D et al (2017) The impact of chronic use of prostaglandin analogues on the biomechanical properties of the cornea in patients with primary open-angle glaucoma. $\mathrm{Br} J$ Ophthalmol 101:120-125. https://doi.org/10.1136/bjophthalmol-2016-308432

33. Miki A, Medeiros FA, Weinreb RN et al (2014) Rates of retinal nerve fiber layer thinning in glaucoma suspect eyes. Ophthalmology 121:1350-1358. https://doi.org/10.1016/j.ophtha.2014.01.017

\section{Figures}




\section{Enrollment}

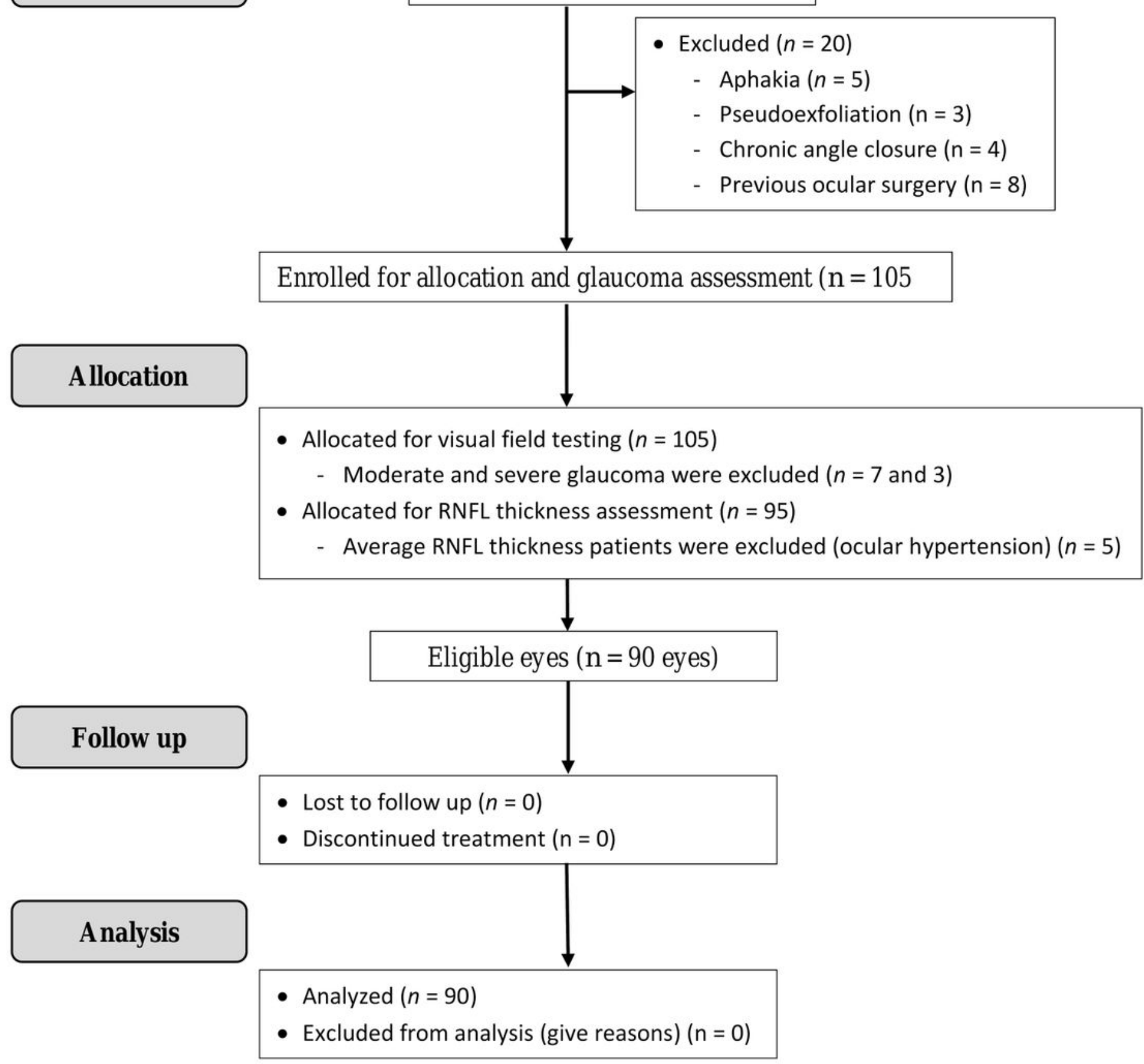

Figure 1

Consort flow diagram of POAG patients' selection. 

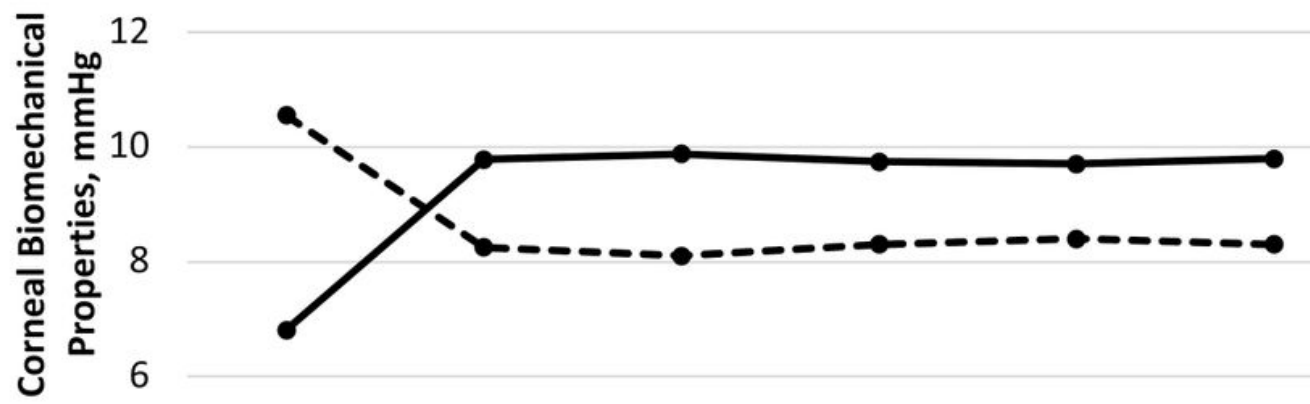

4

\section{Baseline 1 month 3 months 6 months 9 months 12 months}

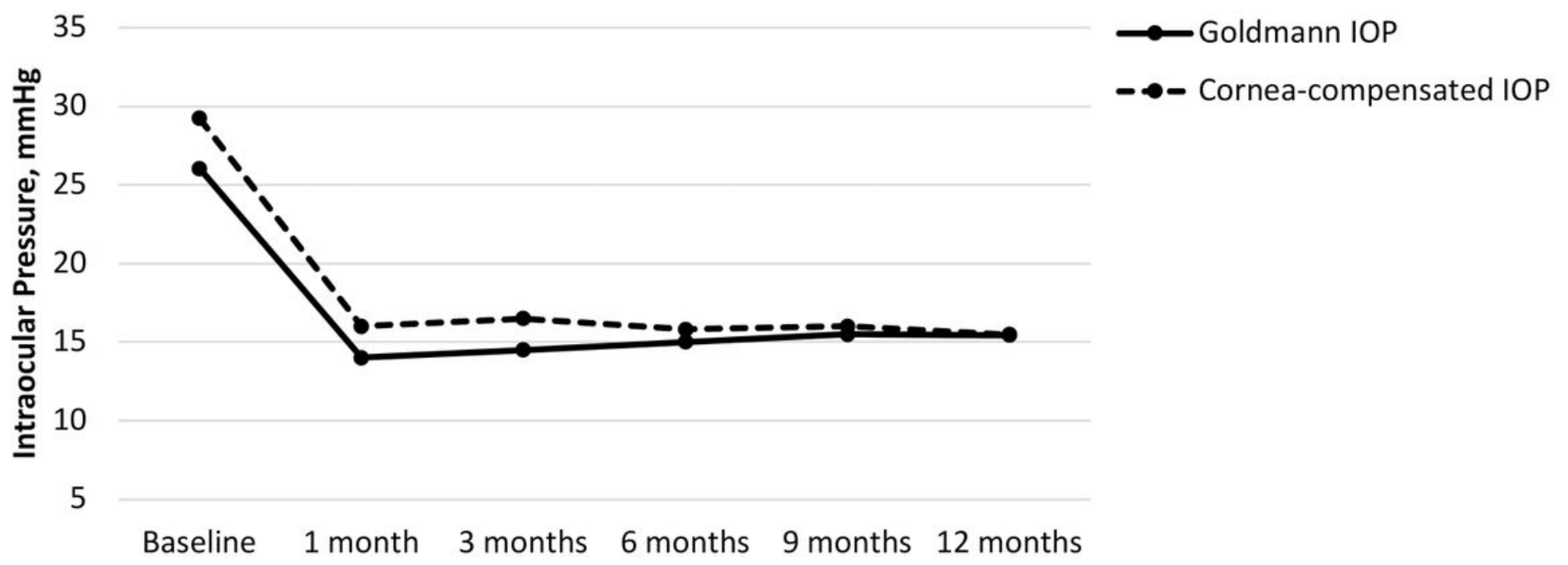

\section{Duration of treatment}

Figure 2

Changes in ocular response analyzer parameters through the follow up period. 

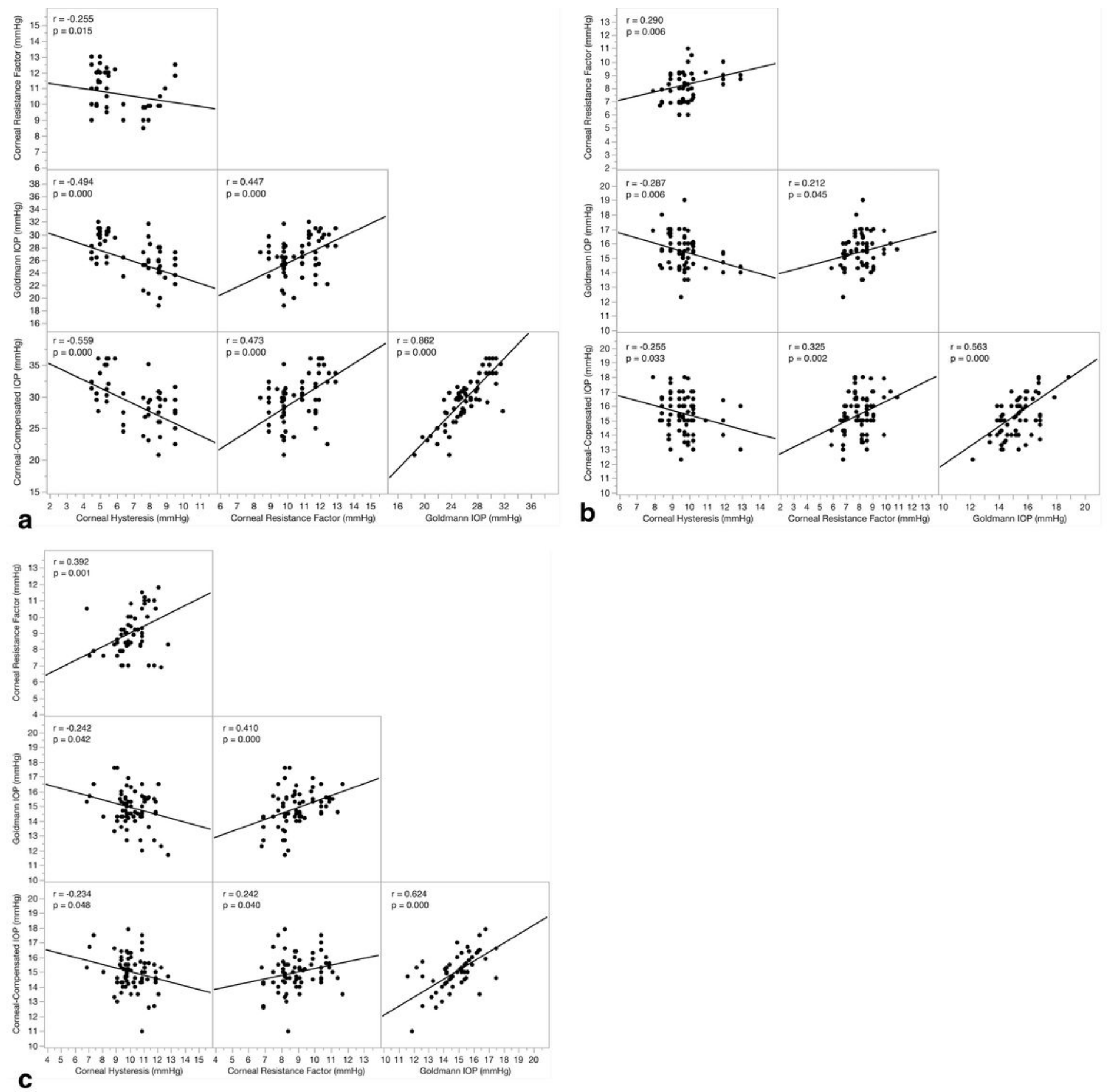

Figure 3

Correlation between ocular response analyzer parameters among POAG patients and controls: (a) At baseline; (b) At the end of 12 months of treatment; (c) Among normal controls. 